\title{
Research on ordering strategy of company D under supply disruption of COVID-19
}

\author{
Xinke $\mathrm{Du}^{1, *}$ \\ ${ }^{1}$ Shanghai Normal University Tianhua College, Business School, Shanghai, China
}

\begin{abstract}
With deepening of economic globalization and prevalence of lean production, market competition has intensified and uncertain risk factors in the cross-supply-demand relationship have increased, thus the supply chain has become much more fragile. Force majeure risks such as natural disasters, epidemics, and traffic accidents further expand the scope and losses of supply disruption. In 2019 the outbreak of COVID-19 pandemic has devastated global supply chains and lead to many companies facing the risk of supply disruptions. Based on the comprehensive analysis of relevant research status, this paper investigates the current situation and existing procurement problems of company D under the risk of supply interruption in the COVID-19 pandemic, and analyzes the procurement strategy response in combination with the actual situation of company D. It combines newsvendor model and the capability option model to analyze the ordering decision of company D and enrich the research on the ordering strategy under supply disruption. The purpose of this paper is to provide company D with scientific procurement advice under supply disruption, and provide a reasonable reference for enterprises in the same industry.
\end{abstract}

\section{Introduction}

At the end of 2019, COVID-19 pandemic broke out globally. Countries and regions immediately introduced measures to lock down cities. Many airlines have to cancel international flights and routes. The global supply chains have been hit by an unprecedented impact[1]. Many manufacturer companies as the core of supply chains have problems of production delays or even shutdown due to the supply disruption. Generally, the possibility of supply disruption is composed of the supply uncertainty of individual suppliers and the possibility of supply disruption of the entire market. The competition mode between supply chains is complex and diversified. Therefore, in COVID-19 pandemic, the more complex the supply network structure is, the greater the possibility of supply disruption can be[2].

Company D was founded in 1995 and has always focused on the global small home appliance market, it is currently the largest exporter of electric kettles and blenders in China, and has been awarded Chinese Wellknown Trademark and Guangdong Export Famous Brand. At the beginning outbreak of COVID-19, affected by national pandemic prevention and quarantine measures, company D had to drop or even stop in production due to supply disruption. As a result, the productivity and capacity utilization of company $\mathrm{D}$ were severely blocked, which seriously affected their sales profit and reputation[3].

This article analyzes ordering decisions of company $\mathrm{D}$ between its principal suppliers and backup suppliers under the risk of supply disruption caused by COVID-19 pandemic. Expected profit function and ordering strategy model based on the newsvendor model and the capacity option model will be established to provide a scientific and reasonable reference for company $\mathrm{D}$ and companies in the same industry under the risk of supply disruption caused by uncertain risks and force majeure.

\section{Overview of The Basic Model}

The supply chain in the newsvendor model is composed of buyers and sellers. Before the product is sold, the buyer purchases the required product from the seller and pays the purchase fee. The buyer will consider the relationship between the order quantity and the demand, the loss of stock out and inventory costs[4]. The manufacturer as the buyer needs to make a trade-off between the loss of stock out and inventory cost and decides the optimal order quantity to make it obtain the maximum expected profit.

The basic model established in this article is a model composed of company D as a manufacturer and two suppliers under the capability option model. The production equipment and the products provided by the two suppliers can meet the quality requirements and engineering production requirement of company $\mathrm{D}$, and the products are replaceable. However, principal supplier has low products cost, but its operation is unstable and supply uncertainty is high, which is much easier to occur supply disruption caused by risk factors. While backup supplier has relatively high product cost, but its

"Corresponding author: dxk2420@sthu.edu.cn 
operation is relatively stable and is not susceptible to occur supply disruption[5].

At the beginning of the ordering cycle, when company $\mathrm{D}$ orders production capacity $\mathrm{N}$ from the backup supplier, it also places orders from the principal supplier. The principal supplier and backup supplier have different ordering proportion and the principal supplier shall have a higher one. When principal supplier has no supply disruption, company $\mathrm{D}$ gives priority to placing orders with it. When the order from the principal supplier can not meet the market demand or the supply of the principal supplier is partially interrupted, company D places orders from the backup supplier with the order quantity less than $\mathrm{N}$. When the principal supplier is completely interrupted, Company D orders products with quantity $\mathrm{N}$ from the backup supplier. After one ordering period ends, if the reserved production capacity is surplus, company D must compensate for the remaining production capacity[6]. The basic order strategy mode considered in this article is shown in following Figure 1:

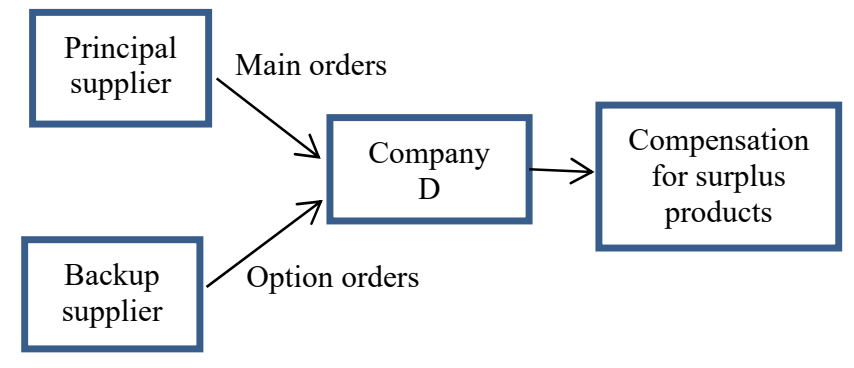

Fig. 1. Capacity option ordering mode of company D under supply disruption

To establish the model and facilitate discussion, variable symbols and meanings introduced in the article are as following Table 1 .

Table1. Model variable symbols and descriptions

\begin{tabular}{|c|c|}
\hline $\begin{array}{c}\text { Symbo } \\
1\end{array}$ & Description \\
\hline$Q$ & $\begin{array}{l}\text { Order quantity of company D to principal } \\
\text { supplier }\end{array}$ \\
\hline$N$ & $\begin{array}{l}\text { Reserved production capacity of company D to } \\
\text { backup supplier }\end{array}$ \\
\hline$C_{1}$ & Unit ordering cost to the principal supplier \\
\hline$C_{2}$ & Unit ordering cost to the backup supplier \\
\hline$P$ & Unit product sales price of company D \\
\hline$L$ & Unit stock-out loss of company D \\
\hline$R$ & Unit residual value of company D's product \\
\hline$\beta$ & $\begin{array}{l}\text { the probability of common supply disruption of } \\
\text { all the suppliers }(0<\beta<1)\end{array}$ \\
\hline$\alpha_{1}$ & $\begin{array}{l}\text { the probability of supply disruption of the } \\
\text { principal supplier }\left(0<\alpha_{1}<1\right)\end{array}$ \\
\hline$\alpha_{2}$ & $\begin{array}{l}\text { the probability of supply disruption of the } \\
\text { backup supplier } \\
\left(0<\alpha_{2}<1\right)\end{array}$ \\
\hline$X$ & $\begin{array}{l}\text { Market random demand, a continuous random } \\
\text { variable }\end{array}$ \\
\hline$f(x)$ & $\begin{array}{l}\text { Probability Function of Market random demand } \\
\text { of company D }\end{array}$ \\
\hline$F(x)$ & $\begin{array}{l}\text { Continuously differentiable and increasing on } \\
\text { interval, } F(x)=0\end{array}$ \\
\hline$g$ & Profit of company D \\
\hline$E(g)$ & Expected profit of company D \\
\hline$e$ & $\begin{array}{l}\text { Unit compensation for unused production } \\
\text { capacity }\end{array}$ \\
\hline
\end{tabular}

In order to facilitate discussion and analysis, the assumptions have been made as following:

(1) All distribution functions established are differentiable and monotone inverse functions.
(2) Company D preferentially orders to the principal supplier, and the unit order cost of the principal supplier must be less than the backup supplier's, which is $C_{1<} C_{2}$.

(3) The probability of supply disruption of the principal supplier is bigger than the backup supplier's, that is $\alpha_{2}<\alpha_{1}$.

(4) The unit sales price must be bigger than the unit ordering cost, stock-out loss and unit residual value to ensure the profit of company D. At the same time, if the supply quantity cannot meet the market demand, company D will have stock-out loss, which must be less than the residual value of the product[7], that is $0<C_{1}<C_{2}<P, R<L$.

(5) Normally, the two suppliers have unlimited production capacity. If a complete disruption occurs and the normal recovery is impossible in a short period of time, company D cannot order goods from the two suppliers[7].

\section{Establishment of Ordering Strategy Model}

Due to the COVID-19 pandemic, both the principal supplier and the backup supplier have possibilities to be affected, and the probability of the supply disruption risks of the two suppliers is different. Therefore, based on the profit assumption of company $\mathrm{D}$, there are four situations as below:

(1) Neither of the two suppliers is interrupted by the risk factors. In this situation, both of them can supply normally, company D preferentially places an order from the principal supplier, and when the principal supplier still cannot meet the market demand, it orders less than or equal to quantity $\mathrm{N}$ from the backup supplier. At the end of the sales period, if there is still excess productivity, company D will compensate for each unit of the product. The probability of this situation 
is $(1-\beta)\left(1-\alpha_{1}\right)\left(1-\alpha_{2}\right)$, the profit of company $\mathrm{D}$ is as follows:

$$
\begin{aligned}
& g_{1}=\int_{0}^{Q}\left[P X-C_{1} Q-e N+R(Q-X)\right] f(x) d x \\
& +\int_{Q}^{Q+N}\left[P X-C_{1} Q-C_{2}(X-Q)-e(N-X+Q)\right] f(x) d x \\
& \int_{Q+N}^{+\infty}\left[P(Q+N)-C_{1} Q-C_{2} N-L(X-Q-N)\right] f(x) d x
\end{aligned}
$$

(2) When the supply of the principal supplier is interrupted by the COVID-19 pandemic, and the backup supplier is unaffected and can supply normally, in this way, company D can exercise the option to place an order from the backup supplier with the ordering quantity less than N. If neither of them can meet market demand, company D will have to face the stock-out loss. The probability of this situation is $(1-\beta)\left(1-\alpha_{2}\right) \alpha_{1}$, and the profit of company $\mathrm{D}$ is as below:

$$
\begin{aligned}
& g_{2}=\int_{0}^{N}\left[P X-C_{2} X-e(N-X)\right] f(x) d x \\
& +\int_{N}^{+\infty}\left[P N-N\left(C_{1}+C_{2}\right)-L(X-N)\right] f(x) d x
\end{aligned}
$$

(3) When the supply of the backup supplier is interrupted by COVID-19 pandemic, but the principal supplier is unaffected and can supply normally, company $\mathrm{D}$ does not need to reserve production capacity from backup suppliers, and can not execute options to obtain goods from it, but company D needs to compensate the backup supplier for each unit of the goods, even the ordered quantity from the principal supplier cannot meet market demand, company D cannot execute options to obtain goods from backup suppliers. Thus company D has to face the stock-out loss and cannot choose other suppliers in time. The probability of this situation is $(1-\beta)\left(1-\alpha_{1}\right) \alpha_{2}$, at this time the profit of company $\mathrm{D}$ is as below:

$$
\begin{aligned}
g_{3}= & \int_{0}^{Q}\left[P X-C_{1} Q+R(Q-X)\right] f(x) d x+e N \\
& \int_{Q}^{+\infty}\left[P(Q+X)-C_{1} Q-L(X-Q)+e N\right) f(x) d x
\end{aligned}
$$

(4) Both the principal supplier and the backup supplier have affected by COVID-19 pandemic and occur supply disruption. In this situation company D can neither order products from the principal supplier nor use the option execution of the production capacity booked with the backup supplier. For a while, it cannot find a qualified supplier to produce products that can meet its requirements, and the products cannot be obtained from other places with high cost, so company D has no choice but has to bear the stock out loss. Thus the probability of this situation is $\beta$, in this case the profit of the company $\mathrm{D}$ is as follows:

$$
g_{4}=\int_{0}^{Q+N}-\operatorname{LXf}(x) d x+\int_{Q+N}^{+\infty}-\operatorname{LXf}(x) d x
$$

Combining above four considerations, formulas from (1) to (4) obtain the expected profit function of company $\mathrm{D}$ for one single cycle order, then the expected benefit of company $\mathrm{D}$ is as below:

$$
\begin{aligned}
& \sum(g)=(1-\beta)\left(1-\alpha_{1}\right)\left(1-\alpha_{2}\right) g_{1}+(1-\beta)\left(1-\alpha_{2}\right) \alpha_{1} g_{2} \\
& +(1-\beta)\left(1-\alpha_{1}\right) \alpha_{2} g_{3}+\beta g_{4}
\end{aligned}
$$

Compute the optimal order quantity of the principal supplier and the optimal reservation production capacity $\mathrm{N}$ of the backup supplier, so as to maximize the expected profit of D company. Then formula (5) can be used to obtain the first-order partial derivatives of $\mathrm{Q}$ and $\mathrm{N}$ respectively, and the calculation results are as follows:

$$
\begin{aligned}
& \frac{\partial \sum(g)}{\partial Q}=(1-\beta)\left(1-\alpha_{1}\right)\left(1-\alpha_{2}\right)\left[\left(R-C_{2}+e\right) F(Q)\right. \\
& \left.\left.+\left(C_{2}-e\right) F(Q+N)-(P+L) F(Q+N)+P-C_{1}+L\right)\right] \\
& \left.+(1-\beta)\left(1-\alpha_{1}\right) \alpha_{2}\left[R F(Q)-(P+L) F(Q+N)+P-C_{1}+L\right)\right] \\
& \quad \frac{\partial \sum(g)}{\partial N}=(1-\beta)\left(1-\alpha_{1}\right)\left(1-\alpha_{2}\right)\left[\left(C_{2}-e\right) F(Q+N)-e F(Q)\right. \\
& \left.\quad-(P+L) F(Q+N)+P-C_{2}+L\right] \\
& \quad+(1-\beta)\left(1-\alpha_{2}\right) \alpha_{1}\left[\left(C_{2}-e\right) F(N)-(P+L) F(Q)+P-C_{2}+L\right]
\end{aligned}
$$

Compute the second order partial derivative of $\mathrm{Q}$ and $\mathrm{N}$ in formula (6) and (7) as below:

$$
\frac{\partial^{2} E(g)}{\partial Q N}=(1-\beta)\left(1-\alpha_{1}\right)\left(1-\alpha_{2}\right)\left[\left(C_{2}-e\right) f(Q+N)-(P+L) f(Q+N)\right]
$$

$\frac{\partial^{2} E(g)}{\partial Q^{2}}=(1-\beta)\left(1-\alpha_{1}\right)\left(1-\alpha_{2}\right)\left[\left(R-C_{2}+e\right) f(Q)\right.$

$\left.+\left(C_{2}-e\right) f(Q+N)-(P+L) f(Q+N)\right]$

$+(1-\beta)\left(1-\alpha_{2}\right) \alpha_{1}[R f(Q)]$

$\frac{\partial^{2} E(g)}{\partial N Q}=(1-\beta)\left(1-\alpha_{1}\right)\left(1-\alpha_{2}\right)\left[\left(C_{2}-e\right) f(Q+N)-e f(Q)\right.$

$-(P+L) f(Q+N)]$

$\frac{\partial^{2} E(g)}{\partial N^{2}}=(1-\beta)\left(1-\alpha_{1}\right)\left(1-\alpha_{2}\right)\left[\left(C_{2}-e\right) f(Q+N)-(P+L) f(Q+N)\right.$

$+(1-\beta)\left(1-\alpha_{2}\right) \alpha_{1}\left[\left(C_{2}-e\right) f(N)-(P+L) f(N)\right]$

Apply the Hessian matrix and get the below result:

$$
\begin{aligned}
& \left|\begin{array}{l}
\frac{\partial^{2} E(g)}{\partial N^{2}} \cdots \frac{\partial^{2} E(g)}{\partial Q N} \\
\frac{\partial^{2} E(g)}{\partial N Q} \cdots \frac{\partial^{2} E(g)}{\partial N^{2}}
\end{array}\right| \\
& D_{1}=\frac{\partial^{2} E(g)}{\partial Q^{2}}<0 \\
& 0<D_{2}=\left|\begin{array}{c}
\frac{\partial^{2} E(g)}{\partial N^{2}} \cdots \frac{\partial^{2} E(g)}{\partial Q N} \\
\frac{\partial^{2} E(g)}{\partial N Q} \cdots \frac{\partial^{2} E(g)}{\partial N^{2}}
\end{array}\right|=\frac{\partial^{2} E(g)}{\partial Q^{2}} \frac{\partial^{2} E(g)}{N^{2}}-\frac{\partial^{2} E(g)}{\partial Q N} \frac{\partial^{2} E(g)}{\partial N Q}
\end{aligned}
$$

Due to $D_{1}<0, D_{2}>0$, it is concluded that the Hessian matrix of the function is negative, so that the optimal order quantity that maximizes the profit function of company $\mathrm{D}$ is the only one that exists. 
Let the first-order partial derivative of $\mathrm{Q}$ and $\mathrm{N}$ be 0 , it can be obtained the optimal order quantity of company $\mathrm{D}$ from the principal supplier and the optimal production capacity booked from the backup supplier, which satisfy the following equation:

$$
\begin{aligned}
& \left(1-\alpha_{2}\right)\left[\left(R-C_{2}+e\right) F(Q)+\left(C_{2}-e\right) F(Q+N)-(P+L) F(Q+N)\right] \\
& +\alpha_{2}[R F(Q)-(P+L) F(Q)]=P-C_{1}-L \\
& \quad\left(1-\alpha_{1}\right)\left[\left(C_{2}-e\right) F(Q+N)-e F(Q)-(P+L) F(Q+N)\right. \\
& +\alpha_{1}\left[\left(C_{2}-e\right) F(N)-(P+L) F(N)\right]=C_{2}-p-L
\end{aligned}
$$

From equation (13) and equation (14), it can be seen that when there are no constraints, the order quantity of company $\mathrm{D}$ to the principal supplier and the reserved production capacity of the backup supplier have nothing to do with $\beta$ (the probability of common supply disruption of all the suppliers). Then the company D's ordering decision is only affected by $\alpha_{1}$ and $\alpha_{2}$.

\section{Case Analysis}

Take company D's PCB board as an example, based on the investigation and research, the model parameter value setting based on hypothesis is shown in Table 2 as below:

Table 2. The main parameter values

\begin{tabular}{|c|c|c|c|c|c|}
\hline Symbol & Value & Symbol & Value & Symbol & Value \\
\hline$P$ & 50 & $\alpha_{1}$ & 0.4 & $C_{1}$ & 20 \\
\hline$\beta$ & 0.05 & $\alpha_{2}$ & 0.2 & $C_{2}$ & 25 \\
\hline $\mathrm{R}$ & 10 & $\mathrm{~L}$ & 15 & $e$ & 3 \\
\hline
\end{tabular}

Put the parameter values in Table 2 into formulas (6) and (7) and can get below:

$$
\begin{aligned}
& 0.8[-12 F(Q)+22 F(Q+N)-65 F(Q+N)]+ \\
& 0.2[10 F(Q)-65 F(Q)]=-45 \\
& -20.6 F(Q)-34.4 F(Q+N)=-45 \\
& 0.6[22 F(Q+N)-3 F(Q)-65 F(Q+N)]+ \\
& 0.4[22 F(N)-65 F(N)]=-40 \\
& -1.8 F(Q)-25.8 F(Q+N)-17.2 F(N)=-40
\end{aligned}
$$

Obviously, the key to the solution is the distribution of demand. Although most of the demand should be normally distributed, yet the solution of the normal distribution is too complicated and beyond my cognition. Moreover, through investigation, it is found that the requirements of the $\mathrm{PCB}$ board studied are relatively close to the uniform distribution. Therefore, this article assumes that the random market demand faced by company $\mathrm{D}$ follows a uniform distribution, that is $\mathrm{X} \sim \mu(\mathrm{a}$, b). Then:

$$
\begin{aligned}
& F(Q)=\frac{Q-a}{b-a} 、 F(N)=\frac{N-a}{b-a} \\
& \text { and } \\
& F(Q+N)=\frac{Q+N-a}{b-a}
\end{aligned}
$$

Within one month, based on customer orders and random demand for repairs, assuming that one of the raw materials for electric toothbrush is PCB board and each unit of PCB can produce one electric toothbrush. The minimum demand for PCB board of company D in one month is about 722 pcs, and the maximum demand is about 5012pcs,so the random demand in the market it faces is $X \sim \mu(722,5012)$. According to formulas (15), (16) and (17), substitute the parameters numbers and obtain: 2115 and 3386. This shows that without constrains, under the risk of supply disruption, company D should purchase approximately $2115 \mathrm{pcs}$ of PCB boards from the principal supplier, and approximately 3386 pcs from the backup supplier. At this time, company D has the largest expected profit.

\section{Conclusion}

In summary, when there are no constraints, the order quantity of company D to the principal supplier and the production capacity of the backup supplier have nothing to do with the probability of common supply disruption of all the suppliers. Then the company D's ordering decision is only affected by $\alpha_{1}$ and $\alpha_{2}$. To deal with different supply disruption, the optimal order quantity can be obtained by setting up a corresponding function to maximize the expected profit of company D. This article only considers the expected profit without constraints. It can also consider the aspect of service level to establish a model to further expand it, make it closer to the reality life, and better solve the enterprise practical problems.

\section{References}

1. Liang, Y.F., Analysis of the impact of COVID-19 epidemic on the world economy, International Economy Cooperation, Vol. 2, No. 02, pp. 4-11 February, 2020.

2. McKibbin, W., Fernando, R., The global macroeconomic impacts of COVID-19: Seven scenarios, CAMA Working Papers, No. 19, pp. 45, March, 2020.

3. C. Weili, The impact of Covid-19 on corporate performance, Modern Business, Vol.12, pp. 90-91, July, 2020.

4. Y. Peng, Research on Manufacturer's Procurement Strategy Selection under Supply Disruption Risk, Ph. D. Thesis, Beijing Jiaotong University, Beijing, China, 2015.

5. X. Yang, Retailer ordering strategy considering transshipment under supply chain disruption risk, PHD Thesis, Hunan University, Hunan, China, 2016. 
6. A. S. Shahed, A. Azeem, S. M. Ali, et a, A supply chain disruption risk mitigation model to manage COVID-19 pandemic risk, Environment Science and Pollution Research, Vol. 10, No. 12, pp. 1-16, 2020.

7. G.Shahryar, F.Scott, The impact of supply disruption risk on a retailer's pricing and procurement strategies in the presence of a substitute product, J.JRETAI, Vol. 10, No. 16, pp.11, 2020. 